\title{
Artificial upwelling using offshore wind energy for mariculture applications
}

\author{
Álvaro Viúdez, Marta Fernández-Pedrera Balsells, Rocío Rodríguez-Marroyo \\ Department of Physical Oceanography and Technology, Institut de Ciències del Mar, CSIC, P. Marítim de la Barceloneta \\ 37-49, Barcelona, Spain.E-mail: aviudez@cmima.csic.es, martafpb@gmail.com, rrodriguez@icm.csic.es
}

\begin{abstract}
Summary: Offshore wind is proposed as an energy source to upwell nutrient-rich deep water to the ocean photic layers. A spar-buoy wind turbine with a rigid tube about $300 \mathrm{~m}$ long is proposed as a pipe to drive deep water up to the surface. The minimum energy required to uplift the water is the potential energy difference between surface waters inside and outside the pipe, which depends on the background density profile. The corresponding surface jump or hydraulic head, $h$, calculated for several analytical and experimental density profiles, is of the order of $10 \mathrm{~cm}$. If the complete turbine power (of the order of several $\mathrm{MW}$ ) is used for raising the water (assuming a 100\% pump efficiency), in a frictionless flow, very large water volumes, of the order of thousands of $\mathrm{m}^{3} \mathrm{~s}^{-1}$, will be transported to the photic layers. In a more realistic case, taking into account pipe friction in wide pipes, of the order of $10 \mathrm{~m}$ radius, and a power delivered to the fluid of $1 \mathrm{MW}$, the volume transport is still very large, about $500 \mathrm{~m}^{3} \mathrm{~s}^{-1}$. However, such a large amount of dense water could sink fast to aphotic layers due to vertical static instability (the fountain effect), ruining the enhancement of primary production. Hence, some ways to increase the turbulent entrainment and avoid the fountain effect are proposed. From the energetic viewpoint, artificial upwelling using offshore wind energy is a promising way to fertilize large open sea regions. This mariculture application is, however, severely subjected to atmosphere and ocean climatology, as well as to ecological dynamics. The general problem is multidisciplinary, and some important physical, engineering and ecological questions need to be seriously addressed to improve our confidence in the approach presented here.
\end{abstract}

Keywords: artificial upwelling; mariculture applications; ocean fertilization; offshore wind energy; spar-buoy wind turbine.

\section{Afloramiento artificial producido con energía eólica con aplicación a la maricultura}

Resumen: Analizamos el uso de la energía eólica marina como fuente de energía para aflorar aguas profundas ricas en nutrientes a las capas fóticas del océano. Una turbina de viento tipo boya-pértiga, con un tubo rígido de unos $300 \mathrm{~m}$ de largo, se propone para transportar las aguas profundas hasta la superficie. La energía mínima necesaria para elevar el agua es la diferencia de energa potencial entre las aguas superficiales dentro y fuera de la tubería, que depende del perfil de densidad de fondo. El salto superficial de agua, o cabezal hidráulico $h$, calculado para varios perfiles analíticos y experimentales de densidad, resulta ser del orden de $10 \mathrm{~cm}$. Si la potencia total de la turbina (del orden de varios MW) se utiliza para elevar el agua (suponiendo una eficiencia de la bomba del 100\%), en un flujo sin fricción, el transporte de volumen de agua transportado a las capas fóticas es muy elevado, del orden de miles de $\mathrm{m}^{3} \mathrm{~s}^{-1}$. En un caso más realista, teniendo en cuenta la fricción en tuberías de un ancho del orden de $10 \mathrm{~m}$ radio, y una potencia proporcionada al fluido de $1 \mathrm{MW}$, el transporte volumen sigue siendo muy grande, de alrededor de $500 \mathrm{~m}^{3} \mathrm{~s}^{-1}$. Sin embargo, una cantidad tan grande de agua densa podría hundirse rápidamente a las capas afóticas debido a la inestabilidad estática vertical (efecto fuente) arruinando la mejora de la producción primaria. Por lo tanto se proponen algunas maneras de aumentar el arrastre turbulento y evitar el efecto fuente. Desde el punto de vista energético, el afloramiento artificial utilizando energía eólica marina parece una manera prometedora de fertilización de grandes regiones del mar abierto. Esta aplicación de maricultura, sin embargo, depende severamente de la climatología atmosférica y océanica, así como de la dinámica ecológica. El problema global es multidisciplinar, y algunos aspectos importantes de física, ingeniería, y ecología tienen que ser mejor estudiados para poder aumentar nuestra confianza en el método aquí presentado.

Palabras clave: afloramiento artificial; aplicaciones a la maricultura; fertilización oceánica; energía eólica marina; turbina eólica tipo boya-pértiga.

Citation/Como citar este artículo: Viúdez A., Fernández-Pedrera Balsells M., Rodríguez-Marroyo R. 2016. Artificial upwelling using offshore wind energy for mariculture applications. Sci. Mar. 80S1: 235-248. doi: http://dx.doi.org/10.3989/ scimar.04297.06B

Editor: J.L. Pelegrí.

Received: June 16, 2015. Accepted: October 14, 2015. Published: September 30, 2016.

Copyright: @ 2016 CSIC. This is an open-access article distributed under the terms of the Creative Commons Attribution (CC-by) Spain 3.0 License. 


\section{INTRODUCTION}

Upwelling of deep water, caused by surface wind stress along the coast, occurs naturally in some oceanic regions and favours high primary production. High primary production regions require both large solar radiation input and a high inorganic nutrient content. The above two requirements seldom occur naturally, and either solar radiation or nutrient concentration becomes a limiting factor inhibiting primary production. High solar radiation and nutrient availability occur simultaneously in surface tropical and subtropical ocean regions where natural upwelling along coastal waters occurs. The scarcity of these natural upwelling regions in the whole ocean and the need to obtain fish resources led to the start of aquaculture activities, first on land and, more recently, in coastal marine environments (Costa-Pierce 2002). However, these activities do not seem to be sufficient to satisfy the fish requirements of an increasing world population (FAO 2010). The message that comes out most clearly from FAO (2010) is the concern that the world fisheries are on a dangerous course (Pauly and Froese 2012).

Scientists are now looking for ways to avoid these limiting factors and fertilize the ocean artificially at a large spatial scale (UNESCO 2010). The activity is known as mariculture (e.g. McKinley and Takahashi 1991), in close relation to aquaculture, which refers to similar fish production activities carried out at smaller spatial scales in land factories. Several attempts at ocean fertilization have been tested. Experiments based on the addition of iron or phosphorus to ocean sites seem to have been concluded negatively (de Baar et al. 2008, UNESCO 2010). Alternative ways to fertilize the ocean are based on the artificial upwelling of nutrient-rich deep waters. This paper proposes an energetically efficient mechanism to upwell deep waters using offshore wind energy.

Several artificial upwelling mechanisms have already been proposed. One of them is to cause upwelling using surface wave energy (Kirke 2003). Wave-powered inertia pump theory (Liu 1999), using a simple pump design originally conceived by Isaacs et al. (1976), predicts a volume transport of $0.45 \mathrm{~m}^{3}$ $\mathrm{s}^{-1}$ from a depth of $300 \mathrm{~m}$ employing a $1.2-\mathrm{m}$ diameter rigid tube. Using a "Bristol Cylinder" (Davis 1990) of $21.5 \mathrm{~m}$ diameter and $40 \mathrm{~m}$ length, Kirke (2003) estimated that a power of $1328 \mathrm{~kW}$ could be obtained in 1.9-m Hawaiian swells and pointed out that such a power would be able to raise $50 \mathrm{~m}^{3} \mathrm{~s}^{-1}$ of water from a depth of $500 \mathrm{~m}$. A recent attempt (White et al. 2010) used an Isaacs wave pump mechanism consisting of a 300 -m-long flexible tube with a one-way valve at the deeper end and the upper end attached by a $15-\mathrm{m}$ cable to a surface buoy. However, this experiment was interrupted early due to material failure caused by the vertical shear and stress of water currents on the tube's flexible material (Kithil 2011, White et al. 2011)). Horizontal pressure differences inside and outside the tube may also have played a role in the material failure. A more complex and robust design was proposed by Salter (2009). This device uses sea wave energy to pump surface warm water downwards through a downtube reaching the thermocline. The warm water will mix with cold, nutrient-rich water, rise to the neutral density layers, and spread sideways. For a wave climate of typical trade-wind sites, and a design including a 100-m-diameter, 200-m-long tube could generate a volumetric flow rate of about $300 \mathrm{~m}^{3} \mathrm{~s}^{-1}$.

An upwelling mechanism based on the particular temperature and salinity vertical gradients of some tropical and subtropical ocean regions was proposed by Stommel et al. (1956). In these regions the temperature and salinity of sea water are higher in surface layers than in deep layers. The density profile remains statically stable due to the large temperature differences, thus counteracting the effect of salinity gradients on the density profile. The mechanism, named the perpetual salt fountain, consists in initially raising cold and low-salinity water along a vertical tube that allows heat exchange. As water raises diabatically, its temperature increases due to the warmer environmental water outside the tube. Since the low salinity remains unchanged during the ascent, the water becomes lighter than the environmental water at every depth $z$, resulting in a perpetual flux of deep water at the upper end of the tube, close to the sea surface. Due to its low efficiency, the perpetual salt fountain was initially considered only an "oceanographic curiosity" (Stommel et al. 1956, Groves 1958). However, this mechanism was recently tested in the ocean (Tsubaki et al. 2007, Maruyama et al. 2011) following an earlier experiment by Maruyama et al. (2004) using a 300-m-long, 0.3-mdiameter tube whose upper end was located at about $60 \mathrm{~m}$ depth. The estimated volume transport was approximately $5.2 \times 10^{-4} \mathrm{~m}^{3} \mathrm{~s}^{-1} \simeq 45 \mathrm{~m}^{3}$ day $^{-1}$.

Artificial upwelling has also been proposed and developed in Norwegian fjords. Upwelling in fjords has been used to prevent the development of toxic dinoflagellates in the upper brackish layer during summer and to favour toxin-free, high-quality mussels (Berntsen et al. 2002, Aure et al. 2007, McClimans et al. 2010). In one case, artificial upwelling was caused by forcing down through a vertical pipe $(27 \mathrm{~m}$ long and $1.25 \mathrm{~m}$ in diameter) surface brackish water using an electrical pump $(60 \mathrm{~kW})$, which produced a downward volume transport of about $2 \mathrm{~m}^{3} \mathrm{~s}^{-1}$ (Aure et al. 2007). Artificial upwelling starts outside the pipe due to the turbulent entrainment of the ascending buoyant plume with the environmental nutrient-rich deep water. In another case, artificial upwelling was caused by a similar vertical plume but forced this time by a 100 -m-long air bubble curtain submerged at about $40 \mathrm{~m}$ depth (McClimans et al. 2010). The estimated vertical flux of deep seawater was $65 \mathrm{~m}^{3} \mathrm{~s}^{-1}$. A third approach to force the upwelling of the unstable buoyant plume (McClimans et al. 2010) used a $26 \mathrm{~m}^{3} \mathrm{~s}^{-1}$ discharged of freshwater at $40 \mathrm{~m}$ depth from a hydropower plant. A diffuser plate at the lower end of the pipe was employed to increase turbulent entrainment. In this case the field experiment showed an entrainment of $117 \mathrm{~m}^{3} \mathrm{~s}^{-1}$ of nutrient-rich deep seawater. These experiments show an increase in nutrients in the euphotic zone resulting in an increase in phytoplankton and a decrease in toxic algae. 
Related also to the upwelling mechanism proposed here is the Japanese TAKUMI project, which was set up in Sagami Bay, Japan in 2003, a prototype of the Ocean Nutrient Enhancer (Ouchi et al. 1998). This device consists of a submersed spar-type floating structure and a steel riser pipe that upwells dense water from 200 $m$ depth and mixes it with light surface water so that the mixed water spreads at its neutral buoyancy depth within the euphotic layer. The resulting volume transport is about $10^{5} \mathrm{~m}^{3}$ day $^{-1} \simeq 1.2 \mathrm{~m}^{3} \mathrm{~s}^{-1}$ (Ouchi 2007). The source of energy of this Ocean Nutrient Enhancer is a diesel generator of about $100 \mathrm{Kw}$, which makes it unsustainable, though other design possibilities based on ocean thermal energy could overcome this problem (Otsuka 2011).

In this article we propose the use of offshore wind as the power source for artificial upwelling. Wind turbine farms are stably operating on land and coastal areas. However, offshore wind energy (Henderson et al. 2003) is being seriously considered as an emerging sustainable complementary source of energy. From the first offshore wind turbine deployed in 1990, cumulative installed power reached 1500 MW in 2009 mainly in northwest European waters (Zaaijer 2009). In the first six months of 2015, 584 commercial offshore wind turbines with a combined capacity totalling 2343 MW were fully grid connected in Europe. Once the 15 commercial wind farms under construction have been completed, the total capacity will be about 4268 MW (EWEA 2015). Offshore wind farms have a higher cost in construction, deployment and maintenance than those on land or in coastal areas. However, the possibility of installing a large number of turbines with a minimum visual impact and the persistence of strong winds in some ocean regions make offshore wind farms an attractive solution to the electric energy demand. Interest in offshore wind farms may increase considering the possibility of using these turbines to favour ocean primary production.

The design proposals for offshore floating wind turbines depend on the way the turbine is stabilized (Jonkman 2009, Jonkman and Matha 2011). One of them, the spar-buoy floating wind turbine, incorporates a long vertical tube (typically $150 \mathrm{~m}$ long) submerged below the turbine's tower that deepens the centre of buoyancy and stabilizes the turbine structure (Roddier and Weinstein 2010, Viré 2012). It seems possible to combine a spar-buoy floating wind turbine with a wave energy converter, with the shape of a torus attached at the basis of the turbine's tower so that wind and wave energy are simultaneously obtained at the same location (Muliawan et al. 2013). The idea that we explore in this work is to use the power of a spar-buoy turbine to raise deep water through an extended spar converted into a long (say $300 \mathrm{~m}$ deep) hollow tube (Fig. 1).

Dense deep water (with density $\rho_{\mathrm{b}}$ ) inside a vertical submerged hollow tube open at the bottom and top ends will sink and, in the state of rest, will cause a negative hydraulic jump (say $h$ ) at the free surface, where pressure equals the atmospheric pressure, because the water column inside the tube is heavier than that outside. The amount of energy $E$ required to pump a mass $M$ of deep

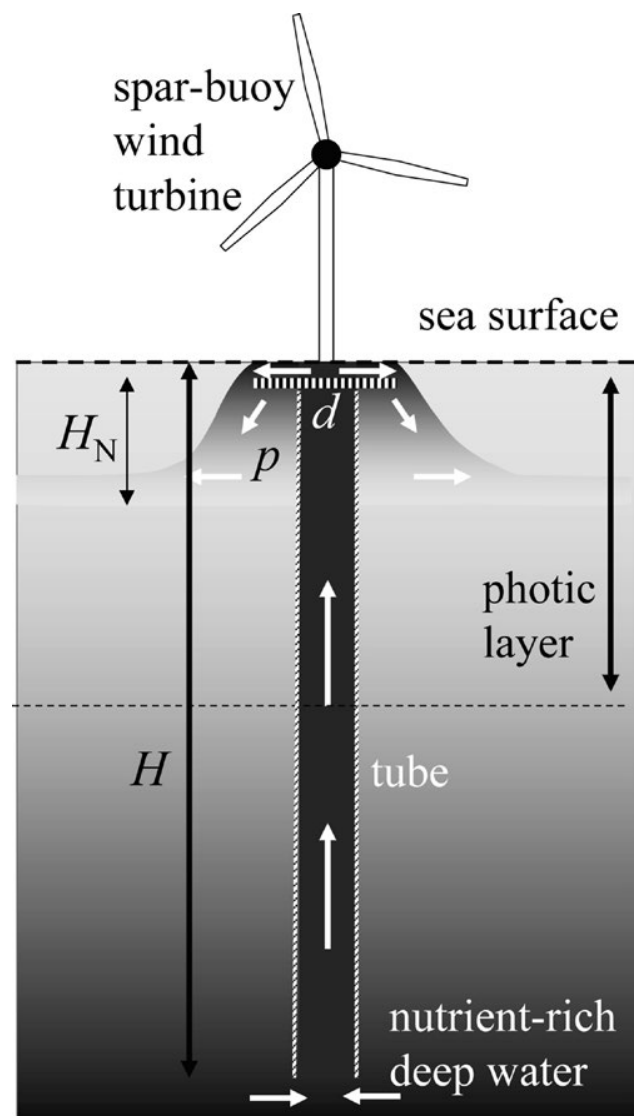

Fig. 1. - Schematic of the spar-buoy turbine upwelling device illustrating its essential (not to scale) parts. Labels indicate the negative buoyant plume $(p)$, the pipe's bottom depth $(H)$, neutral height $\left(H_{\mathrm{N}}\right)$, and diffuser platform $(d)$. White arrows indicate water flow and the grey shade qualitatively indicates nutrient concentration.

water to the surface is therefore the potential energy $E=M g h$, where $g$ is the acceleration due to gravity. The power $P_{\mathrm{w}}$ of the wind turbine and the upward volume transport $F_{\mathrm{v}}$ are therefore related through $P_{\mathrm{w}}=F_{\mathrm{v}} \rho_{\mathrm{b}} g h$, or $F_{\mathrm{v}}=P_{\mathrm{w}} /\left(\rho_{\mathrm{b}} g h\right)$, which provides the upwelling transport through the tube as a function of the turbine's power $P_{\mathrm{w}}$ and the surface hydraulic jump $h$. In the next section we calculate the surface jump $h$, using several background density vertical profiles $\rho(z)$ and therefore provide an estimate of the upwelling transport. It is found that the order of magnitude of $h$ is only $0.1 \mathrm{~m}$, so, due to the large power of wind turbines (typically $P_{\mathrm{w}}=2$ MW) the volume transport could be very large (of the order of $10^{3} \mathrm{~m}^{3} \mathrm{~s}^{-1}$ ). With such a large volume transport, pipe friction can only be neglected if very wide pipes, of the order of $15 \mathrm{~m}$ radius, are used. For thinner pipes, the head loss $h_{\mathrm{f}}$ becomes as important as the hydraulic head and needs to be taken into account. Still, considering pipe friction, the volume transport is very large, of the order of $500 \mathrm{~m}^{3} \mathrm{~s}^{-1}$. Using the turbulent entrainment theory of buoyant plumes it is found that once the dense water has upwelled to the sea surface, it will sink to a neutral height which, depending on the relative depths of the photic layer and thermocline layers, will usually be located below the photic layer, thus making the mechanism useless for primary production enhancement. To avoid this problem, some form of water dilution at the surface must be introduced. Water 
sprinkling, as a way to increase turbulent entrainment and water aeration (as a fountain) is considered, but this process is very energy-consuming. Other mechanical ways requiring no energy consumption, for example introducing a diffuser plate or multiport diffusers, as used for ocean outfall dilution in reverse osmosis desalination plants to reject brine, are also possible. We conclude that, though several important physical, ecological, and engineering questions must be addressed before its effectiveness is proven, artificial upwelling using offshore wind power is a promising approach for enhancing ocean primary production on a large scale.

\section{THE SURFACE JUMP $h$}

In this section we calculate the free surface height difference, or hydraulic head, $h$, between the water column inside and outside the tube for a number of density profiles. To do so we assume hydrostatic balance,

$$
\frac{\partial p}{\partial z}=-g \rho,
$$

where $p(z)$ is the pressure field, $g>0$ is the acceleration due to gravity, $\rho(z)$ is the density field and $z$ is the vertical coordinate. We further assume that, in the steady state, the horizontal pressure gradient at the lower base of the tube is zero, so there is no horizontal flow acceleration in the exterior fluid as it enters the tube. Therefore, at the tube's bottom depth, $z=H$ (subscript b), the interior pressure $p_{\mathrm{i}}(H)=p_{\mathrm{ib}}$ equals the exterior pressure $p_{\mathrm{e}}(H)=p_{\mathrm{eb}}$ below the pump. At the free surface (top, subscript $t$ ) interior and exterior pressures are equal to the atmospheric pressure $p_{\mathrm{a}}$, that is, $p_{\mathrm{e}}(0)=p_{\mathrm{i}}(h)=p_{\mathrm{a}}$. We assume that in the steady state the water inside the tube is homogeneous and has a density equal to the bottom density $\rho(H)$. We therefore neglect density changes as the fluid ascends along the tube. Under these assumptions integration of the hydrostatic condition (1) leads to

$$
\rho(H)(h-H)=\int_{H}^{0} \rho(z) d z,
$$

which means that water masses per unit of horizontal area of the water column inside and outside the tube are equal. From (2) we obtain the solution for the jump $h$,

$$
h=H+\frac{1}{\rho(H)} \int_{H}^{0} \rho(z) d z,
$$

which depends on the length of the tube and on the vertical distribution of background density, $\rho(z)$. Notice that $H<0$, and since $0<\rho(z) \leq \rho(H)$ for $z \in[H, 0]$, we have $H \leq h<0$. We describe next three different solutions for $h$ depending on three different simplified vertical density profiles, $\rho(z)$, and as a fourth case we consider an experimental density profile.

\section{Theoretical models of stratification}

\section{Two-layer model}

The simplest case is that of a two-layer model (see Fig. 2). In the upper layer, where the tube is located, and in the lower layer, below the tube, densities are

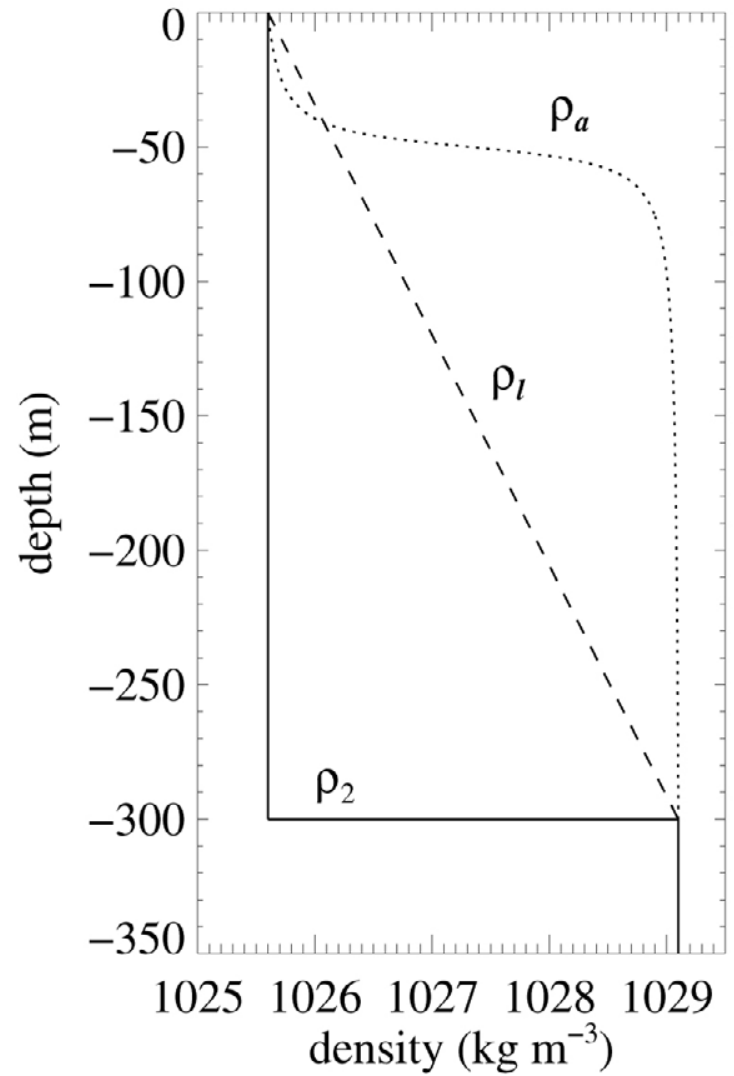

Fig. 2. - The different theoretical density profiles used to compute the surface jump $h$ : the two-layer density profile $\rho_{2}$, the linear density profile $\rho_{\mathrm{l}}$, and the arctangent density profile $\rho_{\mathrm{a}}$ as a function of depth $z$. In this schematic the density boundary values are $\rho_{\mathrm{t}}=$ $1025.5 \mathrm{~kg} \mathrm{~m}^{-3}$ and $\rho_{\mathrm{b}}=1029.1 \mathrm{~kg} \mathrm{~m}^{-3}$.

homogeneous and equal to $\rho_{\mathrm{t}}$ and $\rho_{\mathrm{b}}$, respectively. In this case (see Appendix A) the solution for $h$ is:

$$
h_{2}=H \frac{\rho_{\mathrm{b}}-\rho_{\mathrm{t}}}{\rho_{\mathrm{b}}} .
$$

Thus, in the simplest case $h_{2}$ depends linearly both on $H$ and on the density difference $\rho_{\mathrm{b}}-\rho_{\mathrm{t}}$. We note that, as expected, $h_{2}=0$ when $H=0$ and/or $\rho_{\mathrm{b}}=\rho_{\mathrm{t}}$. Assuming values of $H=-300 \mathrm{~m}, \rho_{\mathrm{b}}=1029 \mathrm{~kg} \mathrm{~m}^{-3}$, and $\rho_{\mathrm{t}}=1026 \mathrm{~kg}$ $\mathrm{m}^{-3}$, typical of the western Mediterranean Sea in the summer season, we obtain $h_{2} \simeq-87 \mathrm{~cm}$. Notice that this profile is an extreme case in the sense that it maximizes the jump $|h|$. An upper density layer deeper than the tube's depth will cause a zero jump, while a shallower layer will cause the weight difference between exterior and interior water column decrease, and therefore will cause a smaller $|h|$.

\section{Linear density profile}

This is the simplest case of a continuously stratified ocean, in which density $\rho_{1}$ is assumed to be linearly dependent with depth, that is, $\rho_{\mathrm{l}}(z) \equiv \rho_{\mathrm{t}}+\vartheta_{0} z$, where $\rho_{\mathrm{t}}=\rho_{\mathrm{l}}(0)$ is the surface density, and $\vartheta_{0}<0$ is a constant density stratification (see Fig. 2). Following the approach described above (see Appendix B) we obtain the surface jump $h_{1}$,

$$
h_{1}=\frac{\vartheta_{0} H^{2}}{2\left(\rho_{\mathrm{t}}+\vartheta_{0} H\right)}=\frac{H}{2} \frac{\rho_{\mathrm{b}}-\rho_{\mathrm{t}}}{\rho_{\mathrm{b}}}=\frac{h_{2}}{2} .
$$


The jump $h_{1}=h_{2} / 2$ because the mass of the background water column (per unit area) in the linear density profile is half that in the two-layer profile. Thus, for the same typical values used previously, we obtain the jump $h_{1}=h_{2} / 2 \simeq-44 \mathrm{~cm}$.

\section{Arctan density profile}

Here we consider a density profile $\rho_{\mathrm{a}}(z)$ that is more realistic than the previous ones in the sense that it reproduces the ocean pycnocline. This profile may be modelled using the arctangent function

$$
\rho_{\mathrm{a}}(z)=c_{1}+c_{2} \arctan \left(c_{3}+c_{4} z\right),
$$

where $c_{1}, c_{2}, c_{3}$, and $c_{4}$ are given constants used to match the $\rho_{\mathrm{a}}$ asymptotes to the boundary values $\rho_{\mathrm{t}}$ and $\rho_{\text {b }}$, and to adjust the pycnocline depth (see Fig. 2 and Appendix C). Integrating (3) we obtain

$$
\begin{gathered}
\rho_{\mathrm{b}}\left(h_{\mathrm{a}}-H\right)=\frac{c_{2}}{c_{4}}\left[c_{3} \arctan \left(c_{3}\right)-\frac{1}{2} \ln \left(c_{3}^{2}+1\right)\right]- \\
-c_{1} H-\frac{c_{2}}{c_{4}}\left(c_{3}+c_{4} H\right) \arctan \left(c_{3}+c_{4} H\right)+ \\
+\frac{c_{2}}{2 c_{4}} \ln \left[\left(c_{3}+c_{4} H\right)^{2}+1\right] \equiv \xi(H),
\end{gathered}
$$

where $\rho_{\mathrm{b}}\left(h_{\mathrm{a}}-H\right)$ and $\xi(H)$ stand for the masses per unit area of the water column inside and outside the tube, respectively. Solving for $h_{\mathrm{a}}$ we get

$$
h_{\mathrm{a}}=H+\frac{\xi(H)}{\rho_{\mathrm{b}}} \text {. }
$$

For the same typical values in the western Mediterranean used previously we obtain $h_{\mathrm{a}} \simeq-18 \mathrm{~cm}$, which has a magnitude smaller than the previous $\left|h_{2}\right|=87 \mathrm{~cm}$ and $\left|h_{1}\right|=44 \mathrm{~cm}$.

\section{Experimental density data}

Finally, we obtain the water jump $h_{\mathrm{e}}$ using experimental in situ density profiles $\rho_{j}\left(t, z_{i}\right)$ representative of the Catalan Sea (western Mediterranean). No offshore wind farm has yet been erected in the Mediterranean, but some studies have already addressed the suitability of climatological Mediterranean offshore winds for profitable energy applications (Lavagnini et al. 2006). The profiles were spatially averaged to produce a representative profile of the region, and time-averaged to produce a representative profile of each season, $\bar{\rho}_{A}\left(z_{i}\right)$ from January to March, $\bar{\rho}_{B}\left(z_{i}\right)$ from April to June, $\bar{\rho}_{C}$ $\left(z_{i}\right)$ from July to September, and $\bar{\rho}_{D}\left(z_{i}\right)$ from October to December. The sampling depths are $z_{i}=\{-0,-10,-20$, $-30,-50,-75,-100,-125,-150,-200,-250,-300\}$ $\mathrm{m}, i=1, \ldots, N=12$. These mean density profiles are plotted in Figure 3. In order to compute $h_{\mathrm{e}}$ for the four mean density profiles (subscript $\mathrm{e}=\{A, B, C, D\}$ ), we use the trapezoidal rule to numerically integrate (3), that is,

$$
h_{\mathrm{e}}=H+\frac{1}{\bar{\rho}_{\mathrm{e}}(N)} \sum_{i=1}^{N-1} \frac{\bar{\rho}_{\mathrm{e}}\left(z_{i}\right)+\bar{\rho}_{\mathrm{e}}\left(z_{i}+1\right)}{2} z_{i},
$$

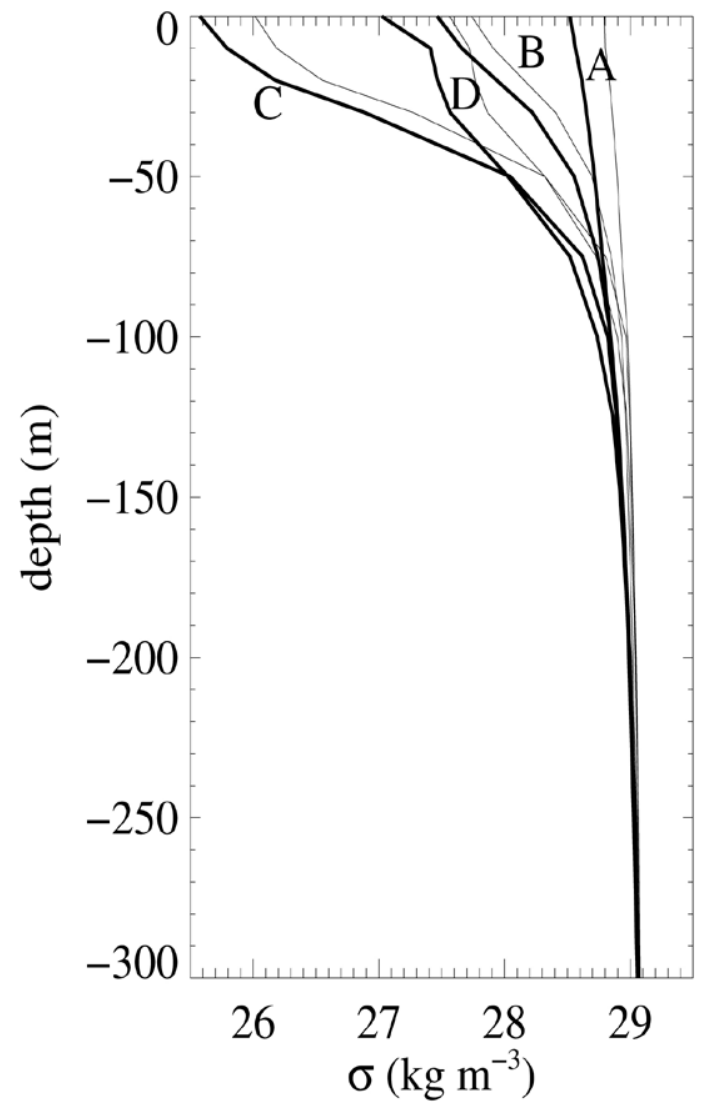

Fig. 3. - Seasonal mean density profiles $\sigma(z)$ (thick lines) in the Catalan Sea, where sigma $\sigma(z) \equiv \rho(z)-10^{3} \mathrm{~kg} \mathrm{~m}^{-3}$. Labels stand for the time periods January-March (A), April-June (B), July-September (C), and October-December (D). The spatial average comprises a total of five hydrographic stations while the time average covers a time period of about three years. Thin lines represent $\sigma(z)$ plus one standard deviation.

where the vertical grid size is non-uniform $\Delta z_{i}=z_{i}-z_{i}+1$. Using (9) and the data $\rho_{\mathrm{e}}$ (Fig. 3), we obtain the jumps $h_{A}=-4.9 \mathrm{~cm}, h_{B}=-8.1 \mathrm{~cm}, h_{C}=-16 \mathrm{~cm}$, and $h_{D}=-12 \mathrm{~cm}$, corresponding approximately to the four seasons.

In winter the reduced solar radiation causes a cooling of the upper ocean and therefore a vertical homogenization of the water ( $\rho_{A}$ in Fig. 3 ). The surface jump $\left|h_{A}\right|=4.9 \mathrm{~cm}$ therefore reaches a minimum value. In spring the surface layer becomes warmer and therefore lighter, so vertical stratification increases. As a consequence, the surface jump increases to $\left|h_{B}\right|=8.1$ $\mathrm{cm}$. In summer, with the pycnocline completely developed, vertical stratification reaches maximum values, and $\rho_{C}$ becomes more similar to the arctangent profile $\rho_{\mathrm{a}}$ (Fig. 2). The surface jump increases to $\left|h_{C}\right|=16 \mathrm{~cm}$ and approaches the jump size of the arctangent profile $\left|h_{\mathrm{a}}\right| \simeq 18 \mathrm{~cm}$. In autumn, surface cooling decreases vertical stratification and therefore the surface jump decreases to $\left|h_{D}\right|=12 \mathrm{~cm}$. The cases described above show that the surface water jump $h$ is only of the order of a few centimetres. This means that very large water volumes inside the tube, of the order of thousands of $\mathrm{m}^{3} \mathrm{~s}^{-1}$, will be transported up if the complete turbine power (also assuming a $100 \%$ pump efficiency) is used to raise the water. Such a huge amount of dense water on the surface runs a risk of sinking fast to 
aphotic layers due to vertical static instability (the so called fountain effect), ruining the enhancement of primary production. This possibility is analysed in a section below. We notice that the power required to raise the deep water is the potential energy associated with the water surface jump $h$ only in the steady state, in which the vertical velocity inside the tube is steady. However, the water volume is initially forced upward from a state of rest, and therefore part of the wind energy must be used to increase the kinetic energy of the water inside the tube. This is a transient effect that, though interesting from the energy balance, is not addressed in this study, which only considers steady state energy balances. We have also assumed that the increase in kinetic energy is negligible and that the water withdrawn within the vertical tube is instantaneously replaced with deep water to keep the hydrostatic balance. This assumes that friction effects in the pipe are negligible, which in turn assumes, given the large volume flux involved, a very large pipe radius, $R$, so the vertical velocity inside the pipe is small. In the next section we consider the loss of power due to the increase in kinetic energy and the loss of power due to friction, which depend on the size of the pipe radius $R$.

\section{LOSS OF POWER DUE TO THE INCREASE IN KINETIC ENERGY AND ENERGY DISSIPATION IN THE PIPE}

The loss of power due to the increase in kinetic energy is simply related to the velocity head $h_{\mathrm{u}}=u^{2} /(2 g)=$ $F_{\mathrm{v}}{ }^{2} /\left(2 g \pi^{2} R^{4}\right)$. We obtain the loss of power due to friction in the pipe, related to the head loss, $h_{\mathrm{f}}$ in hydraulic engineering, using the Darcy-Weisbach equation

$$
h_{\mathrm{f}}=f_{\mathrm{D}} \frac{L}{D} \frac{u^{2}}{2 g},
$$

where $f_{\mathrm{D}}$ is the Darcy-Weisbach friction factor, $u$ is the fluid velocity, and $L$ and $D$ are the length and diameter of the pipe, respectively. Velocity head and head loss can be combined

$$
h_{\mathrm{u}}+h_{\mathrm{f}}=\frac{u^{2}}{2 g}\left(1+f_{\mathrm{D}} \frac{L}{D}\right) .
$$

The Darcy-Weisbach friction factor $f_{\mathrm{D}}$ is obtained from the Colebrook-White equation for Reynolds numbers $\operatorname{Re}>4000$,

$$
\frac{1}{\sqrt{f_{\mathrm{D}}}}=-2 \log _{10}\left(\frac{\varepsilon}{3.7 D}+\frac{2.51}{\operatorname{Re} \sqrt{f_{\mathrm{D}}}}\right),
$$

where $\varepsilon$ is the roughness height of the pipe. For very large Reynolds numbers, $\mathrm{Re}>10^{8}$, corresponding to the expected highly turbulent flow inside the pipe, (12) simplifies to

$$
f_{\mathrm{D}}=\left[-2 \log _{10}\left(\frac{1}{3.7} \frac{\varepsilon}{D}\right)\right]^{-2} .
$$

As a conservative value we take $f_{\mathrm{D}}=0.03$, which approximately corresponds to a very large ratio $\varepsilon / D=$ 0.005 , or a roughness height $\varepsilon=5 \mathrm{~cm}$ for a diameter $D=10 \mathrm{~m}$. Typical roughness height of clean materials are two orders of magnitude smaller than this magnitude, but macro fouling caused by coarse matter, such as algae or mussels, will substantially increase $\varepsilon$.

When changes in kinetic energy and friction are considered, the power provided by the turbine $P_{\mathrm{w}}$ is used to save the hydraulic head $h$ (now taken as a positive quantity), the velocity head $h_{\mathrm{u}}$, and the head loss $h_{\mathrm{f}}$, so the volume flux is

$$
F_{\mathrm{V}}=\frac{P_{\mathrm{W}}}{g \rho_{\mathrm{b}}\left(h+h_{\mathrm{u}}+h_{\mathrm{f}}\right)} .
$$

Replacing $h_{\mathrm{u}}+h_{\mathrm{f}}$ given by (11) in (14) and using $F_{\mathrm{v}}$ $=\pi R^{2} u$, we obtain the depressed cubic equation for the volume flux $F_{\mathrm{v}}$,

$$
F_{\mathrm{v}}^{3} \frac{\rho_{\mathrm{b}}}{2 \pi^{2} R^{4}}\left(1+f_{\mathrm{D}} \frac{L}{2 R}\right)+F_{\mathrm{v}} g \rho_{\mathrm{b}} h-P_{\mathrm{w}}=0 .
$$

For large pipe radius $R$, the first term in (15) may be neglected, and $F_{\mathrm{v}}(R)$ tends to the frictionless solution for slow flows $F_{\mathrm{v}}=P_{\mathrm{w}} /\left(g \rho_{\mathrm{b}} h_{\mathrm{f}}\right)$. The solution of $F_{\mathrm{v}}(R)$ is plotted in Figure 4.

As expected, the increase in kinetic energy and the loss of energy due to friction can only be neglected for a large radius $R$. Given a hydraulic jump $h=0.15 \mathrm{~m}$, a pipe radius $R \simeq 10 \mathrm{~m}$, and a wind turbine providing a power $F_{\mathrm{W}} \simeq 2 \mathrm{MW}$, the resulting volume transport is $F_{\mathrm{v}} \simeq 547 \mathrm{~m}^{3} \mathrm{~s}^{-1}$, which is still a very large volumetric flow. In this case the velocity head $h_{\mathrm{u}} \simeq 0.15 \mathrm{~cm}$ is similar to the hydraulic head $h$, and the head loss $h_{\mathrm{f}} \simeq 0.06 \mathrm{~cm}$ is about $h / 2$. Given the large values of $R$ required to reduce the velocity head and pipe resistance head, we may instead think of the vertical tube or pipe as a wide cylindric container, with open bottom and surface ends, filled with dense deep water, the upper end located above the ocean free surface to avoid entrance of light water. The energy delivered by the wind turbine is used to withdraw the heavy water from this container. In the next section we calculate the horizontal pressure jump across the tube in order to have an insight into the resistance requirements of the tube's materials.

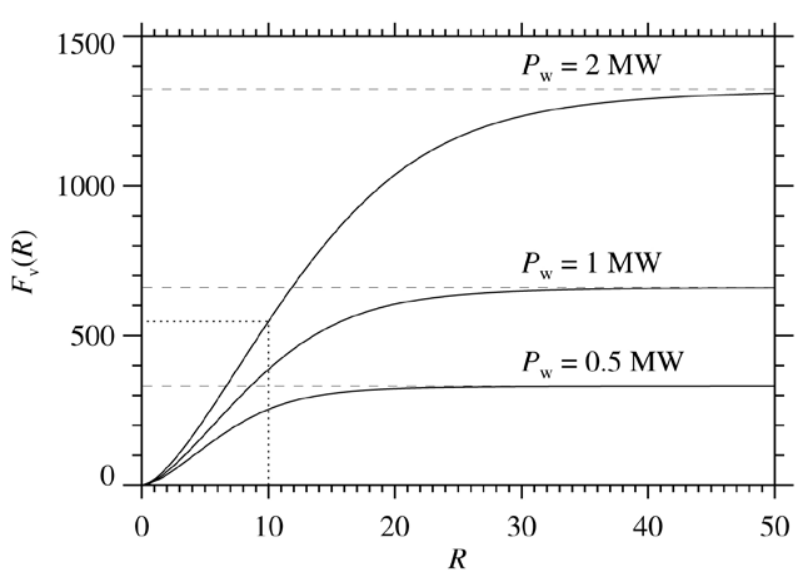

Fig. 4. - The volume flux $F_{\mathrm{v}}(R)$ (in $\mathrm{m}^{3} \mathrm{~s}^{-1}$, thick continuous lines), as a function of the pipe radius $R(\mathrm{~m})$, solution of (15) for three different values of power $P_{\mathrm{w}}$ delivered by the wind turbine. The horizontal dashed lines correspond to the inviscid slow flow limit 


\section{HORIZONTAL PRESSURE JUMP}

The horizontal pressure jump $\Delta p(z)$ across the tube is

$$
p(z)=\left\{\begin{array}{cc}
-p_{\mathrm{e}}(z), & z \geq h_{\mathrm{a}} \\
-p_{\mathrm{e}}(z)+p_{\mathrm{i}}(z), & z<h_{\mathrm{a}},
\end{array}\right.
$$

where $p_{\mathrm{e}}(z)$ and $p_{\mathrm{i}}(z)$ are the hydrostatic pressure of the water column at depth $z$ outside and inside the tube, respectively. In the case of the arctangent density profile, which is the most realistic profile, $\Delta p(z)$ is computed from the integration of (6) from $z$ to $z=0$ for the tube's exterior, and from $z$ to $z=h$ for the tube's interior, giving

$$
\begin{aligned}
p_{\mathrm{e}}(z)= & g \frac{c_{2}}{c_{4}}\left[c_{3} \arctan \left(c_{3}\right)-\frac{1}{2} \ln \left(c_{3}^{2}-1\right)\right]-g c_{1} z- \\
& -g \frac{c_{2}}{c_{4}}\left(c_{3}+c_{4} z\right) \arctan \left(c_{3}+c_{4} z\right)+ \\
& +g \frac{c_{2}}{2 c_{4}} \ln \left[\left(c_{3}+c_{4} z\right)^{2}-1\right]
\end{aligned}
$$

and

$$
p_{\mathrm{i}}(z)=g \rho_{\mathrm{b}}\left(h_{\mathrm{a}}-z\right)
$$

The resulting pressure jump $\Delta p(z)$ is shown in Figure 5. At the ocean surface $\Delta p(0)=0$ since both pressures are equal to the atmospheric pressure. At $z \geq h_{\mathrm{a}}, \Delta p(z)$ equals the (minus) weight (per unit area) of the exterior water column and therefore decreases almost linearly (density differences are very small) along the first $\left|h_{\mathrm{a}}\right|=18 \mathrm{~cm}$. At $h_{\mathrm{a}}=-18 \mathrm{~cm}$ we have

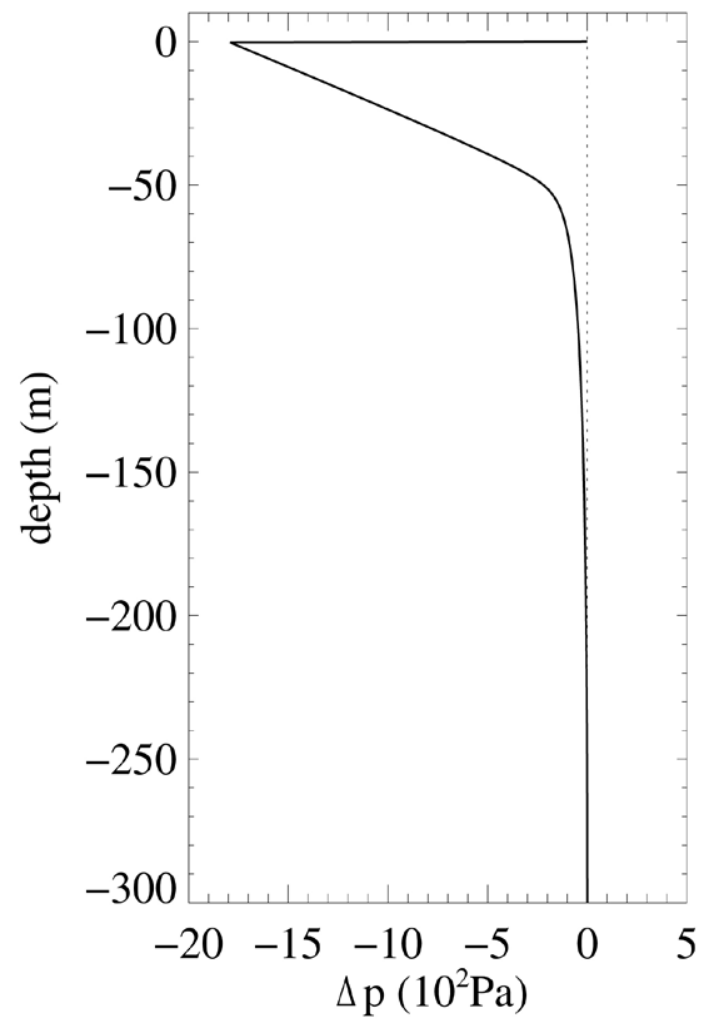

Fig. 5. - Horizontal pressure jump $\Delta p(z)$ across the tube's wall.
$\Delta p\left(h_{\mathrm{a}}\right) \simeq 18 \times 10^{2} P_{\mathrm{a}}=0.18 \mathrm{dbar}$. One dbar approximately corresponds to the hydrostatic pressure of a 1-m-depth water column. At depths $z<h_{\mathrm{a}}$ the pressure jump increases due to the larger weight per unit depth of the interior water column, and reaches $\Delta p=0$ at $z=H$, which was the boundary condition chosen to compute $h_{\mathrm{a}}$. Note that $\Delta p$ increases rapidly from $z=h_{\mathrm{a}}$ to $z \simeq-50 \mathrm{~m}$ since is in this layer where density $\rho_{\mathrm{a}}(z)$ increases fast with depth (Fig. 2). Though this pressure seems to be small, it may be enough to deform flexible material tubes made of very thin ( $0.5 \mathrm{~mm}$ thickness) polyvinyl chloride or polyethylene, such as those used in some upwelling experiments. Thus, some periodic reinforcement of a flexible tube like that done in Maruyama et al. (2011) seems to be necessary. Deployment of a flexible tube in the open ocean, assuring that is initially full of water, is therefore essential for the correct operation of the device. Deformation, including torsion, in the tube caused by vertical shear currents seems to be a more serious problem to the operation of flexible tubes. The structure supporting the pipe will presumably also have an important effect on the pipe. Strain measurements taken in the riser pipe of TAKUMI (Maeda et al. 2007) indicated that the main factor affecting the riser pipe behaviour was not the direct effect of wave and current fields on the pipe, but their indirect effects through the motion of the floating structure.

For a rigid vessel such as that proposed in this study, the circumferential hoop stress $\sigma_{\theta}$ can be obtained using the Barlow thin wall method,

$$
\sigma_{\theta}=\frac{\Delta p^{*} R}{t},
$$

where above $\Delta p^{*}$ is the pressure difference due to the hydraulic head and head loss, $R$ is the pipe radius, and $t$ is the wall thickness. Thus, an order of magnitude of the maximum permissible radius-to-wall thickness $(R / t)$ max required for a stainless steel pipe (maximum allowable stess $\sigma_{\theta}$ max of the order of $10^{2} \mathrm{MPa}$ ) subject to a pressure difference $\Delta p * \simeq 2 \times \Delta p \approx 40 \times 10^{2} \mathrm{~Pa}$, is $(R / t)_{\max } \sim \sigma_{\theta \max } / \Delta p^{*} \sim 25 \times 10^{3}$. For a circular pipe of radius $R=10 \mathrm{~m}$, this implies a minimum wall thickness $t_{\min } \sim 4 \mathrm{~mm}$. Furthermore, horizontal currents will cause a shear force on the tube, which will in turn tend to bend it. Weighting the bottom may help to reduce this problem. Thus, as mentioned before, deformation, including torsion, in the tube by bending moments caused by vertical shear currents seems to be more serious a problem for the operation of the container than the circumferential hoop stress caused by the hydraulic head and head loss.

\section{Neutral height of the sinking plume}

As we have seen in the previous sections, the surface water jump $h$ is only of a few centimetres. The power generated by offshore wind turbines is of the order of several MW. If the complete wind power, say $P_{\mathrm{w}}$, is used to uplift water from $z=h$ to the surface $z=0$, that is, any other energy consuming processes is neglected, the volume flux $F_{\mathrm{v}}$ obtained is 


$$
F_{\mathrm{v}}=\frac{P_{\mathrm{w}}}{g \rho_{\mathrm{b}} h} .
$$

For typical values $P_{\mathrm{w}}=2 \mathrm{MW}, \rho_{\mathrm{b}}=1029 \mathrm{~kg} \mathrm{~m}^{-3}$ and $h=0.16 \mathrm{~m}$, we have a water volume transport estimate $F_{\mathrm{v}} \simeq 10^{3} \mathrm{~m}^{3} \mathrm{~s}^{-1}$. Obviously this is a huge volume flux. Such a volume of water per unit of time with density $\rho_{\mathrm{b}}$ brought to the sea surface, where density ratio $\rho_{\mathrm{b}} /$ $\rho_{\mathrm{t}} \simeq 1.003>1$, will have no time for a complete mixing, and will inevitably lead to a fast sinking of the dense deep water developing a downwelling plume, leaving little time for primary production to develop. Due to the horizontal turbulent entrainment, this vertical plume will later reach a neutral height $H_{\mathrm{N}}$ beyond which no further sinking occurs. Following the classical results of (Morton et al. 1956) for point buoyancy sources, an order of magnitude of $H_{\mathrm{N}}$ is given by

$$
H_{\mathrm{N}}=2.1 \sqrt[4]{\frac{\pi f_{0}}{N^{3}}},
$$

where $f_{0}$ is the surface buoyancy flux and $N$ is the environment Brunt-Väisälä or buoyancy frequency,

$$
N^{2} \equiv \frac{-g}{\rho_{0}} \frac{d \rho_{\mathrm{B}}}{d z},
$$

where $\rho_{0}$ is a constant reference density and $\rho_{\mathrm{B}}(z)$ is the environment (background) density profile. In our case, $f_{0}$ is related to the volume flux $F_{\mathrm{v}}$ by

$$
f_{0}=g^{\prime} \frac{F_{\mathrm{v}}}{\pi}
$$

where $g^{\prime}$ is the reduced gravity

$$
g^{\prime} \equiv g \frac{\rho_{\mathrm{b}}-\rho_{\mathrm{t}}}{\rho_{0}} .
$$

Finally, the neutral height $H_{\mathrm{N}}$ is related to the volume flux $F_{\mathrm{v}}$ through

$$
H_{\mathrm{N}}=2.1 \sqrt[4]{\frac{g^{\prime} F_{\mathrm{v}}}{N^{3}}} .
$$

For the values $g^{\prime}=10(1029-1026) / 1028 \mathrm{~m} \mathrm{~s}^{-2}$, $F_{\mathrm{v}}=10^{3} \mathrm{~m}^{3} \mathrm{~s}^{-1}$, and $N=1 / 50 \mathrm{~s}^{-1}$, we obtain a neutral height $H_{\mathrm{N}} \simeq 90 \mathrm{~m}$, or $H_{\mathrm{N}} \simeq 77 \mathrm{~m}$ for $F_{\mathrm{v}}=500 \mathrm{~m}^{3} \mathrm{~s}^{-1}$. Thus, due to the very large volume flux $F_{\mathrm{v}}$ the nutrient-rich deep water will probably sink to the bottom limit of the photic layer, and primary production will not be considerably enhanced.

To avoid this large vertical sinking, the upwelled water must be dispersed in some way at the surface to increase turbulent entrainment. The point source theory for vertical plumes used above must therefore be modified to include finite area sources. A number of corrections have been developed (Hunt and Kaye 2001) to take into account finite area sources in the theory of turbulent entrainment. A simple estimate may be given by noticing that the angle $\theta$ of the plume's cone (Fig. 6 ) is related to the diameter $D$ of the source and to the virtual height $z_{\mathrm{v}}$ of the point source by

$$
\tan \frac{\theta}{2}=\frac{D}{2 z_{\mathrm{v}}} .
$$

Experimental results show that the total angle $\theta$ en-

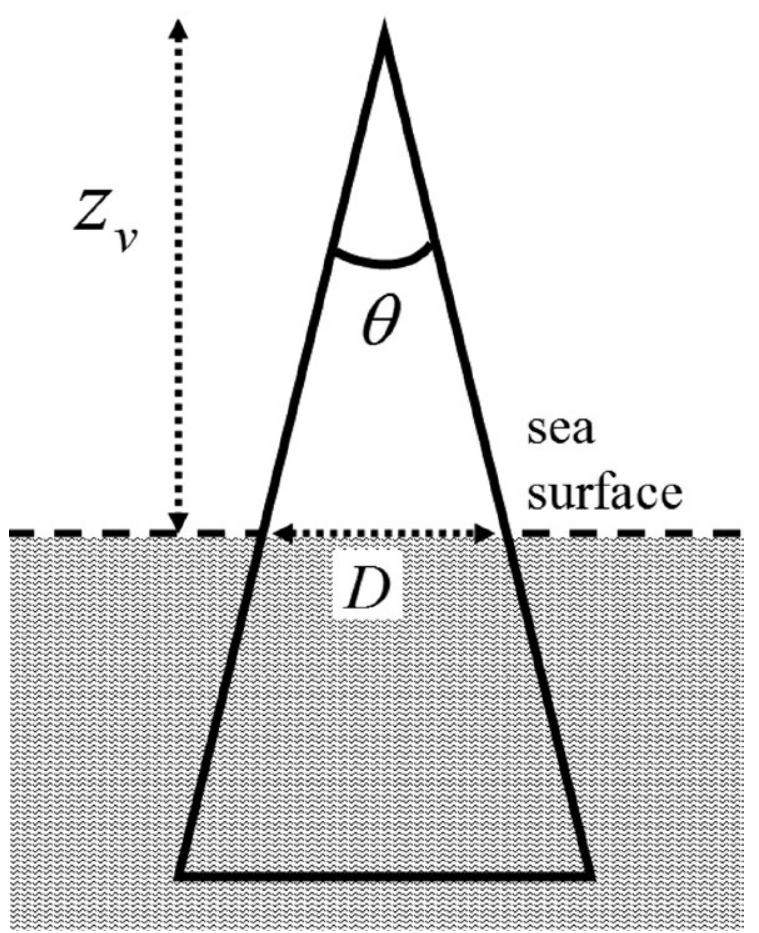

Fig. 6. - Schematic explaining the finite area source symbols.

closed is approximately $18^{\circ}-20^{\circ}$. If the mixed upwelled water is to remain close to the surface, we must impose $z_{\mathrm{v}} \simeq H_{\mathrm{N}}$. Thus, the upwelled water must be dispersed to the surface over a circle of radius $r \sim H_{\mathrm{N}} \tan (\theta / 2) \simeq 15 \mathrm{~m}$. This water dispersion could be achieved by a number of mechanical, non-power-consuming ways. For example, a horizontal perforated disc platform of $15 \mathrm{~m}$ radius located at the surface but below the deep water outflow could work well as a diffuser plate, or multiport diffusers such as those used in ocean outfall dilution could be installed. Note also that this radius $r \simeq 15 \mathrm{~m}$ has an order of magnitude similar to the pipe radius $R$ required to keep power losses due to friction below reasonable low values. However, if oxygen enrichment, or aeration, of the deep water is desirable, a portion of the turbine's energy could be used for water spreading (a fountain aerator) and only the remaining portion will be consumed for water raising. A gross estimation of the order of magnitude of the power required for water sprinkling is given in the next section.

\section{POWER BUDGET CONSIDERING POWER CON- SUMPTION REQUIRED FOR WATER SPRIN- KLING}

In this case the wind power $P_{\mathrm{w}}$ must be employed both for water upwelling $\left(P_{\mathrm{u}}\right)$ and water spreading $\left(P_{\mathrm{s}}\right)$. The larger the water volume transport $F_{\mathrm{v}}$, the larger the amount of energy required for water spreading $P_{\mathrm{s}}$ and the smaller the amount of energy for water upwelling $P_{\mathrm{u}}$, which means the smaller the amount of water transport $F_{\mathrm{v}}$ achieved. An estimate of the power $P_{\mathrm{s}}\left(R, F_{\mathrm{v}}\right)$ consumed for homogeneously sprinkling, over a circle of radius $R$, a volume transport of water $F_{\mathrm{v}}$ leaving a point source located at the circle's centre is given in Appendix D. The basic result is that $P_{\mathrm{s}}\left(R, F_{\mathrm{v}}\right)=(\rho g / 3) R F_{\mathrm{v}}$. We stress 
that the above relation is only a rough estimate of the minimum bound for the ideal power required to spread a volume flux of water $F_{\mathrm{v}}$ over a radius $R$. The practical power $P_{\mathrm{s}}\left(R, F_{\mathrm{v}}\right)$ might be an order of magnitude larger. In order to take this uncertainty into account, we include a factor $\kappa_{0}$ in $\tilde{P}_{\mathrm{s}}$, that is,

$$
P_{\mathrm{s}}\left(R, F_{\mathrm{v}}\right)=\kappa_{0} \frac{\rho_{\mathrm{b}} g}{3} R F_{\mathrm{v}},
$$

and assume that typically $\kappa_{0} \sim 10$. Thus, the variables $P_{\mathrm{u}}, P_{\mathrm{s}}, F_{\mathrm{v}}$ and $R$ are coupled through the following system of equations

$$
\begin{gathered}
P_{\mathrm{w}}=P_{\mathrm{u}}+P_{\mathrm{s}}, \\
F_{\mathrm{v}}=\frac{P_{\mathrm{u}}}{g \rho_{\mathrm{b}} h}, \\
R=2.1 \sqrt[4]{\frac{g^{\prime} F_{\mathrm{v}}}{N^{3}}} \tan \theta, \\
P_{\mathrm{s}}=\kappa_{0} \frac{\rho_{\mathrm{b}} g}{3} R F_{\mathrm{v}},
\end{gathered}
$$

where the unknowns are $\left(P_{\mathrm{u}}, P_{\mathrm{s}}, F_{\mathrm{v}}, R\right)$. By simple substitution we arrive at a single algebraic equation for $F_{\mathrm{v}}$,

$$
F_{\mathrm{v}}\left(\kappa_{0} \frac{2.1}{3} \sqrt[4]{\frac{g^{\prime}}{N^{3}}} \tan \theta F_{\mathrm{v}}^{1 / 4}+h\right)=\frac{P_{\mathrm{w}}}{\rho_{\mathrm{b}} g},
$$

which can be solved numerically noticing that the second term on the left hand side of (32), $F_{\mathrm{v}} h$, is small compared to the first one. For typical values $P_{\mathrm{w}}=2$ MW, $g^{\prime}=0.028 \mathrm{~m} \mathrm{~s}^{-2}, N=1 / 50 \mathrm{~s}^{-1}$, and $\theta=20^{\circ}$, we obtain $F_{\mathrm{v}}=6.3 \mathrm{~m}^{3} \mathrm{~s}^{-1}, R \simeq 9 \mathrm{~m}, P_{\mathrm{s}}=1.99 \mathrm{MW}$, and $P_{\mathrm{u}}=0.01 \mathrm{MW}$. This solution implies that $99.4 \%$ of the wind power will be employed for water sprinkling while only the remaining $0.6 \%$ will be used for raising water at a very reduced volume flux of about $6 \mathrm{~m}^{3} \mathrm{~s}^{-1}$. These results show that water sprinkling, as a way to favour both the turbulent entrainment and oxygen enrichment of the deep water, is very power consuming and, as stated above, use of non-power-consuming diffusion devices such as multiport diffusers or a perforated disc platform is more advantageous.

\section{NUTRIENTS TRANSPORT}

Once we have an estimation of the order of magnitude of the upwelling volume transport (say $F_{\mathrm{v}} \sim 500 \mathrm{~m}^{3}$ $\mathrm{s}^{-1}$, we can also provide an estimation for the transport of nutrients to the photic layer. Time and space averages of vertical profiles of nitrates, phosphates and silicates, characteristics of the Catalan Sea, are given in Figure 7. As a first approximation we can assume that at a depth $z=-300 \mathrm{~m}$ the mass concentration of nitrates, phosphates and silicates is, respectively, $C_{\mathrm{N}}=7 \mu \mathrm{mol}$ $\mathrm{l}^{-1}, C_{\mathrm{P}}=0.4 \mu \mathrm{mol} \mathrm{l}^{-1}$ and $C_{\mathrm{S}}=5 \mu \mathrm{mol} \mathrm{l}^{-1}$. The transport of nutrients to the photic layer is therefore $F_{\mathrm{N}}=C_{\mathrm{N}} F_{\mathrm{v}}$ $\sim 3.5 \mathrm{~mol} \mathrm{~s}^{-1}, F_{\mathrm{P}}=C_{\mathrm{P}} F_{\mathrm{v}} \sim 0.2 \mathrm{~mol} \mathrm{~s}^{-1}$ and $F_{\mathrm{S}}=C_{\mathrm{S}} F_{\mathrm{v}} \sim 2.5$ mol s${ }^{-1}$. This means mass transports $T_{\mathrm{N}} \sim 217 \mathrm{~g} \mathrm{~s}^{-1}=19$ t day ${ }^{-1}, T_{\mathrm{P}} \sim 19 \mathrm{~g} \mathrm{~s}^{-1}=1.6 \mathrm{t} \mathrm{day}^{-1}$ and $T_{\mathrm{S}} \sim 150 \mathrm{~g} \mathrm{~s}^{-1}=13$ $\mathrm{t}$ day $^{-1}$, where we have used the molecular masses $M_{\mathrm{N}} \simeq 62 \mathrm{~g} \mathrm{~mol}^{-1}, M_{\mathrm{P}} \simeq 95 \mathrm{~g} \mathrm{~mol}^{-1}$ and $M_{\mathrm{S}} \simeq 60 \mathrm{~g} \mathrm{~mol}^{-1}$. Typical values of offshore water transport caused by

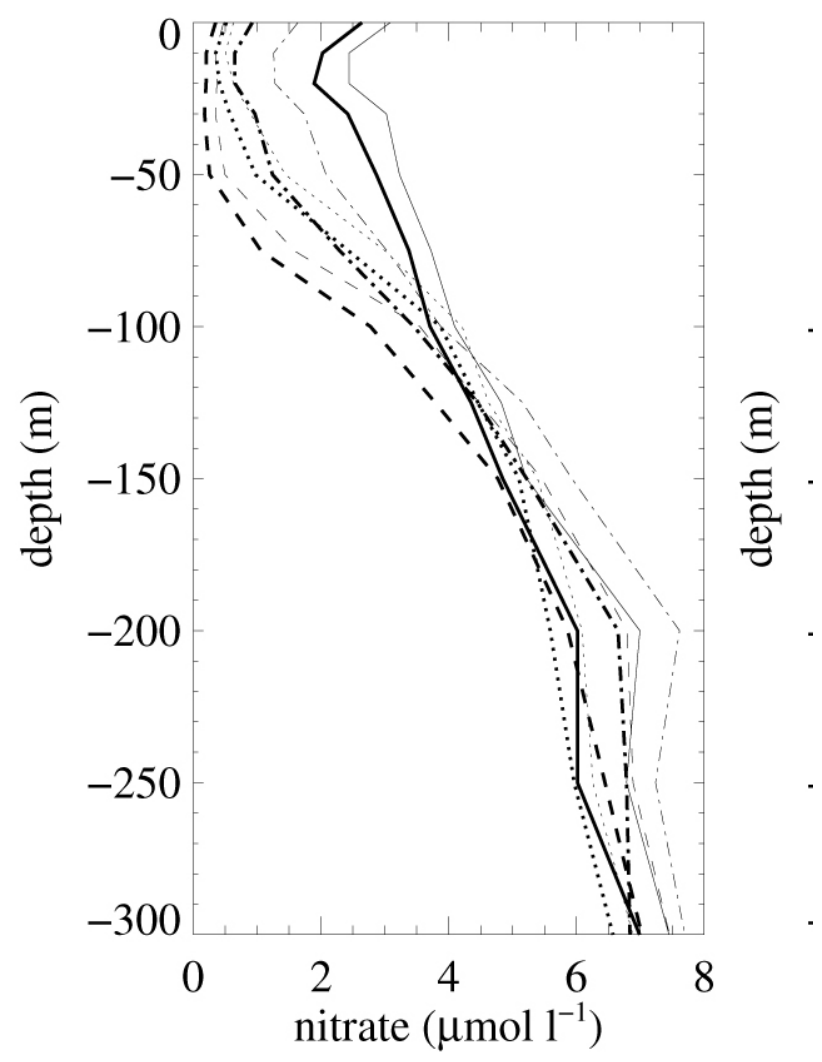

Fig. 7. - Seasonal mean nitrate, phosphate, and silicate profiles for the same time periods as in Figure 3: January-March (solid line), April-June (dotted line), July-September (dashed line), and OctoberDecember (dash-dotted line). Thin lines represent the corresponding value plus one standard deviation.

wind stress in natural upwelling coastal areas are of the order of $10^{3} \mathrm{~m}^{3} \mathrm{~s}^{-1}$ per km of coastline (upwelling index $U=10^{3} \mathrm{~m}^{3} \mathrm{~s}^{-1} \mathrm{~km}^{-1}$ ). Thus, an upwelling $F_{\mathrm{v}} \sim 500$ $\mathrm{m}^{3} \mathrm{~s}^{-1}$ produced by a wind turbine is roughly equivalent to the natural upwelling along a $500 \mathrm{~m}$ coastline.

We notice that large artificial upwelling in an ocean region with poor biological productivity can change the trophic cycle positively or negatively. The sudden growth of primary producers can generate the expected positive response, i.e. a higher productivity with the consequent increase of economically important marine resources. It can also generate a negative response, favouring proliferation of damaging or simply nonautochthonous species that will put an end to the flora and fauna of the region. Short, medium, and large time scale responses of the ecosystem to large artificial upwelling are therefore a very important issue that has been addressed little (McAndrew et al. 2007, Williamson et al. 2009) and needs to be seriously taken into account. The relation between edible fish production and upward flow rate of deep nutrient-rich water also needs to be studied (Groves 1958, Thorson 1961, Matsuda et al. 1999). The ecosystem response is a problem beyond the scope of this work, which only develops, in terms of power requirements, the idea of artificial upwelling using wind power. Artificial upwelling using wind power is, however adjustable, and can be easily reduced, or turned off, if there is any risk of adverse effects to the ecosystem. 


\section{DISCUSSION AND CONCLUDING REMARKS}

In this work we have put forward the idea of taking advantage of in situ offshore wind energy to cause upwelling of nutrient-rich deep water to favour primary production in the ocean. With a wind turbine power of several MW, the order of magnitude of the upward water transport is several hundreds of $\mathrm{m}^{3} \mathrm{~s}^{-1}$, a transport much larger than that achieved using surface wave energy or the perpetual salt fountain mechanism. Here we propose enlarging the spar of a spar-buoy wind turbine to channel the deep water up to the sea surface. This long rigid tube also acts as a ballast, providing additional stability to spar-buoy offshore wind turbines. This work is, however, only a first approximation to the general problem. We basically have found that the upward volume transport could be so large that turbulent water entrainment must be enhanced in some way to avoid sinking of the dense water to a neutral depth below the photic layer. An energetically cheap way to dilute the dense upwelled water is therefore required.

There are still a large number of basic questions that need to be properly addressed. One of them is the ecological response. Though a water rich in nutrients is in theory beneficial to primary production, a large and concentrated source of nutrients may be harmful in an oceanic region where the ecosystem is not yet well adapted to a large availability of nutrients. For example, at the Mississippi mouth excess nutrients carried down the river in floods cause massive algal blooms. A slow startup of the fertilization could therefore be desirable. Since it is planned to obtain offshore wind energy in wind farms comprising a large number of wind turbines, it could be possible to use only a part of the electric power of several wind turbines to raise deep water. This will reduce the upward volume transport assigned to each wind turbine, therefore favouring turbulent entrainment, though it would require an expensive 300-m spar-buoy on each wind turbine. Thus, the benefits of artificial upwelling might largely counteract minor potential negative environmental impacts of offshore wind farms (Wilson et al. 2010).

Another important problem concerns engineering issues. Nutrient-rich water below the photic layer is located in many ocean regions at a minimum depth of about $300 \mathrm{~m}$. This implies the design, manufacturing, testing, and deployment of vertical spars almost twice as large as the ones currently designed for spar-buoy offshore wind turbines (EWEA 2013). Also, since energy losses due to friction in the pipe become large for a reasonable pipe radius, a compromise between wall thickness, pipe radius and upward volume transport must be reached through very careful engineering analysis. Fatigue, stress and load analysis of these new structures need to be carried out.

Some physical oceanographic questions also need to be addressed with great care. Point-like localized upwelling of large water volume transport cannot be maintained for long periods of time unless ocean currents advect the surface mixed water far from the wind turbines and replace it with new, lighter water. Otherwise the complete water column will homogenize into dense water and deep sinking of the upwelled water will occur despite turbulent entrainment. However, while some amount of ocean currents is beneficial to maintain the nutrients in the photic layer, large amplitude currents, and in particular the large vertical shear associated with baroclinic currents, might be detrimental to the stability of the long tube and the turbine's tower. It is therefore important for mariculture applications to select the offshore wind farm location taking into account the wind, wave and ocean current climatology.

The influence of surface waves and shear currents favouring turbulent entrainment needs to be properly investigated. Also, in the absence of significant background ocean shear currents, the upwelled water mixed with the surface water could form large bowls of dense water which, on a time scale of a few days, will start rotating cyclonically, due to the centripetal and Coriolis accelerations, and will approach the cyclogeostrophic balance that is characteristic of mesoscale and submesoscale dynamics. An order of magnitude of the time required to generate a cyclogeostrophic cyclone from a source of deep water can be roughly estimated assuming that in a completely mixed and cyclogeostrophic balanced state the cyclone develops a Gaussian radial (negative) free surface height anomaly $h(r)=h_{0} \exp (-r)$ $r_{0}$ ), where $r$ is the radial distance, $h_{0}<0$ is the height at the vortex centre, and $r_{0} \simeq 20 \mathrm{~km}$ is the horizontal length scale of the vortex. The volume integral of $h(r)$ between $r=0$ and $r=\infty$ is the volume anomaly $V^{\prime}=\pi h_{0} r_{0}{ }^{2}$. The mass anomaly of this vortex is therefore $M^{\prime}=-\rho_{0} V^{\prime}>0$. A constant flux of mass anomaly $F_{\mathrm{m}}^{\prime}=\rho^{\prime} F_{\mathrm{v}}$ will take a time $t=M^{\prime} / F_{\mathrm{m}}^{\prime}=\rho_{0} V^{\prime} /\left(\rho^{\prime} F_{\mathrm{v}}\right)$ to complete the vortex mass anomaly $M^{\prime}$. For $\rho_{0}=10^{3} \mathrm{~kg} \mathrm{~m}^{-3}, \rho^{\prime}=3 \mathrm{~kg} \mathrm{~m}^{-3}, h_{0}=1 \mathrm{~cm}$, $r_{0}=20 \mathrm{~km}$ and $F_{\mathrm{v}}=500 \mathrm{~m}^{3} \mathrm{~s}^{-1}$, we obtain an order of magnitude of the time period $t \sim 10^{7} \mathrm{~s} \sim 10^{2}$ days. This is still too long time a period to neglect the effect of background ocean currents, but if exceptionally quiescent conditions are found, or if several wind turbines are employed, the high volume transports achieved open up the possibility of artificial submesoscale eddy formation. Mesoscale and submesoscale eddies are very coherent stable structures in which mixing with surrounding waters is inhibited. When these vortices leave the upwelling site, they retain the nutrients and other sea water properties for a long time period. In the extreme case of very quiescent waters, an anticyclone may be artificially generated by downwelling light water using a nearby wind turbine. If a cyclone-anticyclone pair is generated close enough, the two vortices will form a dipole vortex which will start translating coherently along the dipole axis. That scenario seems quite simplistic because the upwelling produced by a turbine only occurs when wind is present, so wind stress on the surface ocean layer will likely provide, via turbulent momentum diffusion, enough horizontal momentum to the upper layer waters to avoid generation of shallow eddies, or at least to strongly modify its surface structure. However, we mention this artificial dipole formation because the large vertical transport of water that wind turbines might cause opens up the opportunity to modify the regional submesoscale ocean circulation. On the other hand, large wind farms may 
produce a significant disturbance on the surface wind stress, generating upwelling/downwelling velocities in the wind wake that might affect the local ecosystem (Broström 2008).

As an overall conclusion we might say that, from the energetic point of view, artificial upwelling using offshore wind energy seems to be a promising way to enhance primary production in the ocean. Mariculture application of this approach implies the fertilization of large regions in the open ocean, and is therefore severely subjected to atmosphere and ocean climatology, as well as to ecological dynamics. The political issues also need to be addressed: if productivity is enhanced in the open ocean, costs and benefits must be properly distributed among the interested countries. The general problem is a multidisciplinary one, and we have noticed that some important physical, engineering, and ecological questions need to be seriously addressed to obtain a more complete confidence in the approach presented here.

\section{ACKNOWLEDGEMENTS}

We thank two anonymous reviewers for their very useful comments. Partial support for this study was obtained through projects CTM2011-28867 and CTM2014-56987-P (Spanish Ministry of Science and Innovation).

\section{REFERENCES}

Aure J., Strand Ø., Erga S.R., et al. 2007. Primary production enhancement by artificial upwelling in a western Norwegian fjord. Mar. Ecol. Prog. Ser. 352: 39-52 http://dx.doi.org/10.3354/meps07139

Berntsen J., Aksnes D.L., Foldvik A. 2002. Production enhancement by artificial upwelling: a simulation study. Hydrobiology 484: $177-190$. http://dx.doi.org/10.1023/A:1021317424276

Broström G. 2008. On the influence of large wind farms on the upper circulation. J. Mar. Syst. 74: 585-591 http://dx.doi.org/10.1016/j.jmarsys.2008.05.001

Costa-Pierce B.A. 2002. Ecological Aquaculture: The Evolution of the Blue Revolution. Blackwell Science, $382 \mathrm{pp}$.

Davis J. 1990. Wave energy absorption by the Bristol Cylinderlinear and non-linear effects. Proc. Inst. Civil Eng. 89: 317-340. http://dx.doi.org/10.1680/iicep.1990.9394

de Baar H.J.W., Gerringa L.J.A., Laan P., et al. 2008. Efficiency of carbon removal per added iron in ocean iron fertilization. Mar. Ecol. Prog. Ser. 364: 269-282. http://dx.doi.org/10.3354/meps07548

EWEA. 2013. Deep water - The next step for offshore wind energy. Tech. rep. European Wind Energy Association.

EWEA. 2015. The European offshore wind industry - key trends and statistics 1st half 2015. Tech. rep. European Wind Energy Association

FAO. 2010. The state of the world fisheries and aquaculture. Rome: Food and Agriculture Organization of the United Nations.

Groves G.W. 1958. Flow estimate for the perpetual salt fountain. Deep Sea Res. 5: 209-214. http://dx.doi.org/10.1016/0146-6313(58)90013-3

Henderson A.R., Morgan C., Smith B., et al. 2003. Offshore wind energy in Europe - a review of the state-of-the-art. Wind Energ. 6: 35-52. http://dx.doi.org/10.1002/we.82

Hunt G.R., Kaye N.G. 2001. Virtual origin correction for lazy turbulent plumes. J. Fluid Mech. 435: 377-396. http://dx.doi.org/10.1017/S0022112001003871

Isaacs J.D., Castel D., Wick G.L., 1976. Utilization of the energy in ocean waves. Ocean Eng. 3: 175-187.

http://dx.doi.org/10.1016/0029-8018(76)90022-6
Jonkman J.M. 2009. Dynamics of offshore floating wind turbines model development and verification. Wind Energ. 12: 459-492. http://dx.doi.org/10.1002/we.347

Jonkman J.M., Matha D. 2011. Dynamics of offshore floating wind turbines - analysis of three concepts. Wind Energ. 14: 557-569. http://dx.doi.org/10.1002/we.442

Kirke B. 2003. Enhancing fish stocks with wave-powered artificial upwelling. Ocean Coast. Manag. 46: 901-915. http://dx. doi.org/10.1016/S0964-5691(03)00067-X

Kithil P.W. 2011. Comments on "An open ocean trial of controlled upwelling using wave pump technology". J. Atmos. Ocea. Tech., 28: 847-849. http://dx.doi.org/10.1175/2010JTECHO778.1

Lavagnini A., Sempreviva A.M., Transerici C., et al. 2006. Offshore wind climatology over the Mediterranean Basin. Wind Energ. 9: 251-266. http://dx.doi.org/10.1002/we.169

Liu C. 1999. Research on artificial upwelling and mixing at the University of Hawaii at Manoa. IOA Newslett. 10: 1-8.

Maeda K., Takahashi I., Miyabe H., et al. 2007. Strain measurement on riser pipe of TAKUMI. Proceedings of the Seventh ISOPE Ocean Mining Symposium, Lisbon, Portugal, The International Society of Offshore and Polar Engineers.

Maruyama S., Tsubaki K., Taira K., et al. 2004. Artificial upwelling of deep seawater using the perpetual salt fountain for cultivation of ocean desert. J. Oceanogr. 60: 563-568. http://dx.doi.org/10.1023/B:JOCE.0000038349.56399.09

Maruyama S., Yabuki T., Sato T., et al. 2011. Evidences of increasing primary production in the ocean by Stommel's perpetual salt fountain. Deep-Sea Res. I 58: 567-574. http://dx.doi.org/10.1016/j.dsr.2011.02.012

Matsuda F., Szyper J., Takahashi P., et al. 1999. The ultimate ocean ranch. Sea Technol. 40(8): 17-26.

McAndrew P.M., Björkman K.M., Church M.J., et al. 2007. Metabolic response of oligotrophic plankton communities to deep water nutrient enrichment. Mar. Ecol. Prog. Ser. 332: 63-75. http://dx.doi.org/10.3354/meps332063

McClimans T.A., Handå H., Fredheim A., et al., 2010. Controlled artificial upwelling in a fjord to stimulate non-toxic algae. Aquac. Eng. 42: 140-147. http://dx.doi.org/10.1016/j.aquaeng.2010.02.002

McKinley K.R., Takahashi P.K. 1991. Deep ocean water, artificial upwelling, and open ocean mariculture: A promise for the future. IEEE 1: 195-199. http://dx.doi.org/10.1109/OCEANS.1991.613930

Morton B.R., Taylor G.I., Turner J.S. 1956. Turbulent gravitational convection from maintained and instantaneous sources. Proc. R. Soc. Lond. 234: 1-23. http://dx.doi.org/10.1098/rspa.1956.0011

Muliawan M.J., Karimirad M., Moan T. 2013. Dynamic response and power performance of a combined Spar-type floating wind turbine and coaxial floating wave energy converter. Renew. Energy 50: 47-57. http://dx.doi.org/10.1016/j.renene.2012.05.025

Otsuka K. 2011. Inclusive Impact Index Triple I and its application for Ocean Nutrient Enhancer. Proceedings of the Twenty-first International Offshore and Polar Engineering Conference, International Society of Offshore and Polar Engineers.

Ouchi K. 2007. Three years operation of ocean nutrient enhancer TAKUMI in Sagami Bay. Seventh ISOPE Ocean Mining Symposium, 1-6 July, Lisbon, Portugal, International Society of Offshore and Polar Engineers.

Ouchi K., Yamatogi T., Kobayashi K., et al. 1998. Density Current Generator-A new concept machine for agitating and upwelling a stratified water. Ocean Community Conference, 1, Baltimore, MD, USA, The Marine Technology Society, 129-136.

Pauly D. Froese R. 2012. Comments on FAO's State of Fisheries and Aquaculture, or 'SOFIA 2010'. Mar. Pol. 36: 746-752. http://dx.doi.org/10.1016/j.marpol.2011.10.021

Roddier D., Weinstein J. 2010. Floating wind turbines. Mech. Eng. 132: $28-32$.

Salter S.H. 2009. A 20 GW thermal 300-metre3/sec wave-energised, surge-mode nutrient pump for removing atmospheric carbon dioxide, increasing fish stocks and suppressing hurricanes. Proceedings of the 8th European Wave and Tidal Energy Conference, Uppsala, Sweden.

Stommel H., Arons A.B., Blanchard D. 1956. An oceanographical curiosity: the perpetual salt fountain. Deep-Sea Res. 3: 152-153. http://dx.doi.org/10.1016/0146-6313(56)90095-8

Thorson J. 1961. Flow estimate for an artificial upwelling in the sea. 
Deep Sea Res. (1953) 7(4): 296-297. http://dx.doi.org/10.1016/0146-6313(61)90050-8

Tsubaki K., Maruyama S., Komiya A., et al. 2007. Continuous measurement of an artificial upwelling of deep sea water induced by the perpetual salt fountain. Deep-Sea Res. I 54: 75-84. http://dx.doi.org/10.1016/j.dsr.2006.10.002

UNESCO 2010. Ocean fertilization. A scientific summary for policy makers. $17 \mathrm{pp}$.

Viré A. 2012. How to float a wind turbine. Rev. Environ. Sci. Biotechnol. 11: 223-226. http://dx.doi.org/10.1007/s11157-012-9292-9

White A., Björkman K., Grabowski E., et al. 2010. An open ocean trial of controlled upwelling using wave pump technology. J. Atmos. Ocean. Tech. 27: 385-396.

http://dx.doi.org/10.1175/2009JTECHO679.1
White A.E., Letelier R.M., Björkman K.M., et al. 2011. Reply. J. Atmos. Ocean. Tech. 28: 850-851.

http://dx.doi.org/10.1175/2010JTECHO796.1

Williamson N., Komiya A., Maruyama S., et al. 2009. Nutrient transport from an artificial upwelling of deep sea water. J. Oceanogr. 65: 349-359.

http://dx.doi.org/10.1007/s10872-009-0032-x

Wilson J.C., Elliott M., Cutts N.D., et al. 2010. Coastal and offshore wind energy generation: Is it environmentally benign? Energies 3(7): 1383-1422.

http://dx.doi.org/10.3390/en3071383

Zaaijer M.B. 2009. Review of knowledge development for the design of offshore wind energy technology. Wind Energ. 12: 411-430.

http://dx.doi.org/10.1002/we.349

\section{APPENDICES}

\section{Appendix A. - Surface jump in the two-layer model}

Using the hydrostatic approximation (1), the pressure outside the tube is

$$
\int_{H}^{0} \frac{\partial p_{1}}{\partial z} \partial z=-\int_{H}^{0} \rho_{\mathrm{t}} g d z
$$

whose integration is

$$
p_{1}(0)-p_{1}(H)=g \rho_{\mathrm{t}} H,
$$

or $p_{1}(H)=p_{\mathrm{a}}-g \rho_{\mathrm{t}} H$, where $p_{\mathrm{a}}$ is the atmospheric pres-

whose integration is

$$
p_{2}(h)-p_{2}(H)=-g \rho_{\mathrm{t}}(h-H),
$$

or $p_{2}(H)=p_{\mathrm{a}}-g \rho_{\mathrm{b}}(h-H)$. The height $h$ is obtained assuming that in the steady state there is no horizontal pressure gradient at $z=H$, i.e., $p_{1}(H)=p_{2}(H)$, so

$$
h=H \frac{\rho_{\mathrm{b}}-\rho_{\mathrm{t}}}{\rho_{\mathrm{b}}} .
$$

sure. Inside the tube,

$$
\int_{H}^{h} \frac{\partial p_{2}}{\partial z} \partial z=-\int_{H}^{h} \rho_{\mathrm{b}} g d z
$$

\section{Appendix B. - Surface jump in the linear density profile}

Using the hydrostatic approximation (1), the pressure outside the tube is

$$
\int_{H}^{0} \frac{\partial p_{1}}{\partial z} d z=-g \int_{H}^{0}\left[\rho_{\mathrm{t}}+\vartheta_{0} z\right] d z
$$

whose integration is

$$
p_{1}(0)-p_{1}(H)=g \rho_{\mathrm{t}} H+g \vartheta_{0} \frac{H^{2}}{2},
$$

or

$$
p_{1}(H)=p_{\mathrm{a}}-g \rho_{\mathrm{t}} H-g \vartheta_{0} \frac{H^{2}}{2},
$$

where $p_{\mathrm{a}}$ is the atmospheric pressure. Inside the tube,

$$
\int_{H}^{h} \frac{\partial p_{2}}{\partial z} d z=-g \int_{H}^{h} \rho_{\mathrm{b}} d z
$$

and integrating,

$$
p_{2}(H)=p_{\mathrm{a}}-g \rho_{\mathrm{b}}(H)(h-H) .
$$

Assuming that in the steady state there is no horizontal pressure gradient at $z=H$, i.e., $p_{1}(H)=p_{2}(H)$, we obtain

$$
-p_{\mathrm{t}}-\vartheta_{0} \frac{H^{2}}{2}=\rho_{\mathrm{t}} h-\rho_{\mathrm{t}} H+g \vartheta_{0} H h-\vartheta_{0} H^{2},
$$

and solving for $h$,

$$
h=\frac{\vartheta_{0} H^{2}}{2\left(\rho_{\mathrm{t}}+\vartheta_{0} H\right)} .
$$




\section{Appendix C. - Surface jump in the arctangent density profile}

The objective here is to find an arctangent density profile $\rho(z)$ of the form

$$
\rho(z)=c_{1}+c_{2} \arctan \left(c_{2}+c_{3} z\right),
$$

where $c_{1}, c_{2}, c_{3}$ and $c_{4}$ are constants. To do so, we first linearly map the depth range $\left[z_{\min }, z_{\max }\right]$ into the range of the tangent function $\left[Z_{\min }, Z_{\max }\right]=\left[-\tan \left(X_{\max }\right),-\tan \left(X_{\min }\right)\right]$, where $\left[X_{\max }, X_{\min }\right]=[1.55,-1.47]$ are values slightly [smaller, larger] than $[\pi / 2,-\pi / 2]$. These values are chosen so that the vertical arctangent asymptotes adjust to the upper and lower density values, as well as to match the pycnocline depth to about $z=50 \mathrm{~m}$.

Therefore,

$$
Z(z)=Z_{\min }+\left(z-z_{\min }\right) \frac{Z_{\max }-Z_{\min }}{z_{\max }-z_{\min }},
$$

Finally, the arctangent profile $\arctan [Z(z)]$ is linearly mapped into the density profile $\rho(z)$, that is,

$$
\frac{\rho_{\mathrm{t}}-\rho(z)}{\rho_{\mathrm{t}}-\rho_{\mathrm{b}}}=\frac{\arctan \left(Z_{\max }\right)-\arctan [Z(z)]}{\arctan \left(Z_{\max }\right)-\arctan \left(Z_{\text {min }}\right)},
$$

Thus, we obtain the constants,

$$
\begin{gathered}
c_{1}=\rho_{\mathrm{t}}-\frac{\left(\rho_{\mathrm{t}}-\rho_{\mathrm{b}}\right) \arctan \left(Z_{\max }\right)}{\arctan \left(Z_{\max }\right)-\arctan \left(Z_{\min }\right)}, \\
c_{2}=\frac{\rho_{\mathrm{t}}-\rho_{\mathrm{b}}}{\arctan \left(Z_{\max }\right)-\arctan \left(Z_{\min }\right)}, \\
c_{3}=Z_{\text {min }}-\frac{z_{\text {min }}\left(Z_{\text {max }}-Z_{\text {min }}\right)}{z_{\text {max }}-z_{\text {min }}}, \\
c_{4}=\frac{Z_{\text {max }}-Z_{\text {min }}}{z_{\text {max }}-z_{\text {min }}} .
\end{gathered}
$$

Given the depth range $\left[z_{\min }, z_{\max }\right]=[-300,0] \mathrm{m}$, and the density range $\left[\rho_{\mathrm{b}}, \rho_{\mathrm{t}}\right]=[1029.1,1025.6] \mathrm{kg} \mathrm{m}^{-3}$, we obtain $\left\{c_{1}, c_{2}, c_{3}, c_{4}\right\}=\{1027.0,-0.66190,9.9666,0.19987\}$.

Once the arctangent density profile $\rho(z)$ has been found, we need to integrate it in order to obtain the pressure field outside the tube,

$$
\int_{z_{\min }}^{z_{\max }} \rho(z) d z=\int_{z_{\min }}^{z_{\max }}\left[c_{1}+c_{2} \arctan \left(c_{3}+c_{4} z\right)\right] d z
$$

The arctangent integral

$$
c_{2} \int_{z_{\min }}^{z_{\max }} \arctan \left(c_{3}+c_{4} z\right) d z
$$

is done by a change of variable,

$$
x \equiv c_{3}+c_{4} z, d x=c_{4} d z
$$

Therefore

$$
\begin{gathered}
c_{2} \int \arctan (x) \frac{d x}{c_{4}}= \\
=\frac{c_{2}}{c_{4}} \int \arctan (x)= \\
=\frac{c_{2}}{c_{4}}\left[x \arctan (x)-\frac{1}{2} \ln \left(x^{2}+1\right)\right]= \\
=\frac{c_{2}}{c_{4}}\left[\left(c_{3}+c_{4} z\right) \arctan \left(c_{3}+c_{4} z\right)-\frac{1}{2} \ln \left\{\left(c_{3}+c_{4} z\right)^{2}+1\right\}\right]_{z_{\min }}^{z_{\max }} .
\end{gathered}
$$

And hence, the pressure outside the tube, 


$$
\begin{gathered}
p_{1}(0)-p_{1}(H)= \\
=-g\left[c_{1} z+\frac{c_{2}}{c_{4}}\left(c_{3}+c_{4} z\right) \arctan \left(c_{3}+c_{4} z\right)-\frac{1}{2} \ln \left\{\left(c_{3}+c_{4} z\right)^{2}+1\right\}\right]_{H}^{0},
\end{gathered}
$$

and finally,

$$
\begin{gathered}
p_{1}(0)-p_{1}(H)= \\
=-g \frac{c_{2}}{c_{4}}\left[c_{3} \arctan \left(c_{3}\right)-\frac{1}{2} \ln \left(c_{3}^{2}+1\right)\right]+ \\
+g c_{1} H+\frac{g c_{2}}{c_{4}}\left(c_{3}+c_{4} H\right) \arctan \left(c_{3}+c_{4} H\right)+ \\
+\frac{g c_{2}}{2 c_{4}} \ln \left[\left(c_{3}+c_{4} H\right)^{2}+1\right]
\end{gathered}
$$

Inside the tube

$$
p_{2}(0)-p_{2}(H)=-g \rho_{\mathrm{b}}(h-H) .
$$

Equating $p_{1}(0)=p_{2}(0)=p_{\mathrm{a}}$, and $p_{1}(H)=p_{2}(H)$, we obtain $(8)$.

\section{Appendix D. - Power required for water sprinkling}

In this appendix we estimate the order of magnitude of the power $P_{\mathrm{s}}\left(R, F_{\mathrm{v}}\right)$ required for sprinkling a water volume transport $F_{\mathrm{v}}$ over a circle of radius $R$. The initial kinetic energy density $E_{0}$ of a water particle of density $\rho$ leaving the circle centre with horizontal $u_{0}$ and vertical $w_{0}$ velocity components is

$$
E_{0}=\frac{1}{2} \rho\left(u_{0}^{2}+w_{0}^{2}\right),
$$

From the equations of uniformly accelerated motion $r(t)=u_{0} t$ and $z(t)=w_{0} t-1 / 2 g t^{2}$, we see that the initial kinetic energy required to throw a water particle a horizontal distance $r$ reaches a minimum when

$u_{0}=w_{0}=\sqrt{r g / 2}$, and hence the kinetic energy density

$$
E_{0}(r)=\frac{\rho g}{2} r
$$

The area differential is $d A(r)=2 \pi r d r$ and the energy differential is $d E(r)=E_{0}(r) H d A(r)=\rho g \pi H r^{2}$ $d r$, where $H$ is a unit of vertical length. Therefore, the energy $E(R)=(\rho g \pi H / 3) R^{3}$. As a function of the upwelling volume transport $F_{\mathrm{v}} \equiv \pi R^{2} W=\pi R^{2} H / T$, where $T \equiv H / W$ is the time interval taken to advance a length $H$ at a vertical velocity $W$. Finally the power consumed for water spreading $P_{\mathrm{s}}\left(R, F_{\mathrm{v}}\right) \equiv E(R) / T$ is

$$
P_{\mathrm{s}}\left(R, F_{\mathrm{v}}\right)=\kappa_{0} \frac{\rho g}{3} R F_{\mathrm{v}} .
$$

We stress that the above relation is only a rough estimate of a minimum bound for the ideal power required to spread a volume flux of water $F_{\mathrm{v}}$ over a radius $R$. The practical power might be an order of magnitude larger. In order to take this uncertainty into account, we have included a factor $\kappa_{0}$ in $P_{\mathrm{s}}$, assuming that typically $\kappa_{0} \sim 10$. 